\title{
Factors Affecting Children's Cholesterol Levels with a View to Prevent Cardiovascular Disease-The Unique Benefits of Health Screening at the Elementary School
}

\author{
Akihiro Kihara', Hiromi Kawasaki²*, Satoko Yamasaki², Mika Nishiyama ${ }^{3}$, Md. Moshiur Rahman² \\ ${ }^{1}$ Graduate School of Biomedical \& Health Sciences, Hiroshima University, Hiroshima, Japan \\ ${ }^{2}$ Institute of Biomedical \& Health Sciences, Hiroshima University, Hiroshima, Japan \\ ${ }^{3}$ Department of Welfare, Hiroshima Bunkyo Women's University, Hiroshima, Japan \\ Email: a-kihara81183@pref.hiroshima.lg.jp, *khiromi@hiroshima-u.ac.jp, morisato@hiroshima-u.ac.jp, \\ mnishiyama@h-bunkyo.ac.jp,moshiur@hiroshima-u.ac.jp
}

How to cite this paper: Kihara, A., Kawasaki, H., Yamasaki, S., Nishiyama, M. and Rahman, Md.M. (2017) Factors Affecting Children's Cholesterol Levels with a View to Prevent Cardiovascular Disease-The Unique Benefits of Health Screening at the Elementary School. Health, 9, 172-188. http://dx.doi.org/10.4236/health.2017.91012

Received: December 14, 2016

Accepted: January 21, 2017

Published: January 24, 2017

Copyright (C) 2017 by authors and Scientific Research Publishing Inc. This work is licensed under the Creative Commons Attribution International License (CC BY 4.0).

http://creativecommons.org/licenses/by/4.0/

\begin{abstract}
Background: The prevention of cardiovascular disease (CVD) can substantially contribute to reducing the mortality rate across countries. The level of interest in cholesterol among experts increases when the subjects are elderly and obese individuals. However, specialists do not recommend that children should receive the cholesterol test. The objective of this study was to investigate the distribution of cholesterol levels among the children of public school and their parents' lifestyles that are associated with cholesterol levels, and to assess the need for and utility of cholesterol testing in school settings. Methods: The study investigated a group of 226 fourth-grade public school children aged between 9 and 10 years and guardians in Akitakatacity of Hiroshima Prefecture, Japan. Multiple regression analyses were performed with the logarithmic value of cholesterol levels as a response variable, awareness about lifestyles and health of children as an explanatory variable, and child's sex and body mass index (BMI) as moderating variables. Using questionnaires about lifestyles, the step-down procedure was applied in multiple regression analyses to narrow down relevant lifestyle variables. Results: The percentage of children with the high total cholesterol (TC) value was about 15 and with low-density lipoprotein (LDL) cholesterol value was about 10. Children with low high-density lipoprotein (HDL) cholesterol value were 5\%. Treatment was not required according to the comprehensive assessment. Cholesterol levels were associated with the situation of the children and their guardians as follows, guardian need to consider the food, and child has the correct knowledge about food like how to eat snacks. Conclusions: Children had poor cholester-
\end{abstract}


ol levels. From childhood, along with the parents, there is a need to learn about appropriate level of cholesterol for CVD prevention.

\section{Keywords}

Children's Lifestyle-Related Disease, Cardiovascular Disease, Health

Promotion for Family, School Health

\section{Introduction}

Cardiovascular disease (CVD) accounts for $31 \%$ of global mortality according to the World Health Organization (WHO) [1]. It is the second leading cause of death in Japan after malignant neoplasms, according to a cause-of-death analysis by the Japan Ministry of Health, Labour and Welfare [2]. These figures suggest that prevention of CVD would substantially contribute to reducing the mortality rate of CVD across countries. The risks of CVD are associated with body mass index (BMI) and levels of blood lipids such as total cholesterol (TC), triglycerides (TG), low-density lipoprotein (LDL) cholesterol, and high-density lipoprotein (HDL) cholesterol [3]. The National Heart, Lung, and Blood Institute (NHLBI) developed the National Cholesterol Education Program (NCEP) to draw greater attention of experts to cholesterol level in blood [4]. The NCEP aims to reduce CVD deaths through emphasizing the importance of monitoring cholesterol, limiting lipid containing food intake, and lowering cholesterol levels.

To prevent CVD, experts recommend focused guidance and support targeting communities, children, and in-office settings [4]. The level of interest in blood cholesterol among experts increases when it comes to elderly and obese individuals. This is due to a high incidence of CVD deaths among people of middle and advanced age group [5] [6]. Specialists have recommended for adults that it is necessary to include the serum cholesterol test in the medical check-up. However, specialists do not recommend that children should receive the serum cholesterol test. Blood cholesterol levels have been reported to increase after the age of 15 years in the United States (US) [3] [7]. One study in the Finnish population found that the blood cholesterol level at the age of 12 years is associated with the level in adulthood [8]. In Japan, Tan et al. tested the cholesterol of children aged 8 to 10 years, and conducted the testing again 4 years later. There was evidence of a correlation between cholesterol levels at ages 8 to 10 years and 4 years later [9]. Studies have shown that children who begin to put on weight in their early years have significantly higher cholesterol levels after they reach adulthood [10]. In another study, Kouda et al. found that childhood cholesterol levels have been on the rise yearly due to dietary changes [11]. Given that childhood cholesterol levels are predictors of adult cholesterol levels, when today's children reach adulthood, they may develop arteriosclerosis more advanced than that of adults now a days with increased risks for CVD. As recommended by the NHLBI, it is important to give attention to cholesterol level in the beginning of childhood. 
The fact that cholesterol is associated with lifestyle variables such as exercise and diet is well established in case of adults. The same association is also indicated for children [9]. As the cholesterol level begins to increase at around the age of 15 years [8], it is necessary to check the childhood cholesterol levels through cholesterol testing in children between the ages of 8 and 10 years. Childhood cholesterol testing programs have been conducted and studied, some of which have yielded childhood cholesterol testing and reference values [12] [13] [14] [15]. However, these reference values were established for the purpose of screening for familial hyperlipidemia. Persons with familial hypercholesterolemia have caused highly elevated cholesterol levels since childhood. Their cholesterol level rapidly increased to high levels with age [16]. They are at high risk for CVD and require early treatment [17], and therefore relatively high reference cholesterol levels have been established.

Cholesterol tests for screening purposes are not universally performed; they are advised at a rate of 4.3\% [18] of health visits in the US. An accurate percentage of cholesterol screening at schools in Japan is unknown, because cholesterol screening at schools is not required by law. As a preventative measure for lifestyle diseases, cholesterol levels should receive closer attention to achieve reductions in the CVD related mortality rate. The objective of the present study was to investigate the distribution of cholesterol levels among public school children, the children along with their parents' lifestyles associated with cholesterol levels and to assess the need for cholesterol testing in school settings.

\section{Methods}

\subsection{Study Population}

The study investigated a group of 226 fourth-grade public school children in Akitakata city of Hiroshima Prefecture, Japan, born between 2005 and 2006, aged 9 and 10 years. All the children of the fourth grader in the public elementary schools who were agreed to perform the blood test of Akitakata city were the targets of this study. It is because it carried out as public health service to the city. There was a notice by the informational magazine of the town and invitation by the school teachers.

\subsection{Lifestyle Questionnaire}

The survey form referred to the investigation item of many fields for a Japanese child and was created by the researchers. For example, the investigations to which we referred are the investigation of a movement custom, and investigation of a meal, which can cover all a child's lives. Those investigations are conducted by the organization of the country which called it the Ministry of Health, Labour and Welfare and the Ministry of Education, Culture, Sports, Science and Technology. The investigation for a child consisted of 55 items, and for the gurdian of 70 items. As the teachers expected educational effects, the questionnaires for children were distributed a total of 3 times: Round 1 in July, Round 2 in September, and Round 3 in November. The questionnaires for parents were distri- 
buted at the same time as the Round 1 questionnaires for the children in July. The questionnaires were brought home by the children, who then submitted their sealed completed questionnaires to the school. Blood samples were collected in late September to accommodate school events. The children and the parents shared the same identification number assigned by the school.

\subsection{Procedure for Blood Tests}

Following the distribution of study information to parents by the local government, parents registered their children for blood sampling, at that time the presence of allergy to rubbing alcohol was checked. As a fasting blood sampling was necessary, blood drawing was conducted right before lunch. Prior to blood sampling, the children watched our informational video to learn about blood and blood sampling procedures.

For cost limitations, blood samples were tested to find out the same laboratory examination reports as in the general health checkups for adults: anemia, blood glucose, kidney function, lipid profile, and liver function. Analysis of cholesterol was performed as follows: TC was measured by the cholesterol oxidase method, LDL cholesterol and HDL cholesterol were measured by the direct (enzymatic) method, and TG was measured by the enzyme colorimetric method. The need for treatment was determined holistically by the school physician based on the reference data (for 10-year-olds) from the National Center for Child Health and Development.

\subsection{Data Collection and Statistical Analysis}

Responses from the children were standardized by converting them into normal scores in a way that averaged out the three responses. Responses from the child and guardian were quantified where questions with binary answers were converted into dummy variables (0 or 1), and questions with four possible answers were standardized by converting them into normal scores with a mean of 0 and a standard deviation of 1 . Multiple regression analyses were performed with the logarithmic value of cholesterol levels as a response variable, awareness about lifestyles and health of children as an explanatory variable, and child's sex and BMI as moderating variables. Sex and BMI were used as moderating variables for LDL cholesterol, as the LDL cholesterol level differs between the sexes [18] and is strongly associated with BMI [19]. Using a large number of questions on lifestyles, the step-down procedure was applied in multiple regression analyses to narrow down relevant lifestyle variables. In the first stage, explanatory variables with $\mathrm{P}$-values less than 0.7 were retained and then re-analyzed. In the second stage, variables with $\mathrm{P}$-values less than 0.4 were retained. In the third stage, variables with $\mathrm{P}$-values less than 0.15 were finally selected as explanatory variables.

\subsection{Ethical Considerations}

Consent and support for the study were obtained after the health management 
department of the local government explained the need for and the benefits of the blood tests, as well as anticipated risks to the education department and teachers of each participating school. Similar briefing sessions were organized for parents, where information materials were distributed. The registration form for blood sampling also contained information on the need for and the benefits of blood sampling, as well as anticipated risks. The registration form was distributed to the parents by the local government, along with a document explaining that study findings would be made public as a published article while ensuring the anonymity and confidentiality of participants. Results from the questionnaires and blood tests were assigned unique codes different from individual identifiers, making the data untraceable to any particular individual. For the analysis, we borrowed the Excel datasets processed by the local government. These procedures were reviewed by an ethical committee (Approval number E-493).

\section{Results}

Eighty-three percent (189/226) of the eligible school children at Akitakata city participated in the blood cholesterol testing. Reference values used for judging the test results and reporting to parents were data on Japanese 10-year-olds from the National Center for Child Health and Development. The results represented higher levels than those reported by Okada et al. [12]. The reference values used by the local government were as follows: TC $125-230 \mathrm{mg} / \mathrm{dL}$ for both boys and girls; LDL < $170 \mathrm{mg} / \mathrm{dL} ; \mathrm{HDL} \geq 40 \mathrm{mg} / \mathrm{dL}$; and TG 36 - $138 \mathrm{mg} / \mathrm{dL}$ for boys and $41-138 \mathrm{mg} / \mathrm{dL}$ for girls. The highest BMI was 24.8 for boys and 31.3 for girls, the highest TC level was $247 \mathrm{mg} / \mathrm{dL}$ for boys and $279 \mathrm{mg} / \mathrm{dL}$ for girls, the highest LDL level was $169 \mathrm{mg} / \mathrm{dL}$ for boys and $197 \mathrm{mg} / \mathrm{dL}$ for girls, and the lowest HDL level was $37 \mathrm{mg} / \mathrm{dL}$ for boys and $38 \mathrm{mg} / \mathrm{dL}$ for girls. No children were determined holistically to be in need of treatment by the local government. Table 1 shows the characteristics by sex. Boys showed significantly higher TC levels. Table 2 shows cholesterol levels by each percentile. Table 3 shows time-use characteristics, with significantly longer sleeping time for girls $(\mathrm{P}=0.035)$ and significantly longer exercise time for boys $(P=0.009)$. Table 4 shows the contents of the choices. Table 5 shows lifestyle variables and preferences associated with TC, LDL cholesterol, HDL cholesterol, TC, and TG as response variables.

Variables of children associated with higher TC levels were as follows: past dieting experience $(P=0.0068)$, not eating heavily seasoned foods $(P=0.0032)$, shorter exercise time $(P=0.0009)$, skipping breakfast $(P=0.0070)$, and having likes and dislikes $(P=0.0095)$. Variables of parents associated with higher LDL cholesterol levels were as follows: views of the child's body weight not matching the height $(P=0.0019)$, negative views towards eating a lot during childhood $(P=0.0099)$, not supervising the amount of child's snacks $(P=0.0006)$, ensuring not to skip meals $(\mathrm{P}=0.0009)$, not eating heavily seasoned food $(\mathrm{P}=$ 0.0077), valuing an exercise-friendly environment $(P=0.0039)$, not addressing likes and dislikes although paying attention to child's health $(P=0.0059)$, not 
Table 1. Anthropometric variables in 9 to 10-year-old children in Akitakata city, Hiroshima, Japan.

\begin{tabular}{|c|c|c|c|c|c|c|c|c|c|c|c|}
\hline \multirow[b]{3}{*}{ Height $(\mathrm{cm})$} & \multicolumn{4}{|c|}{ Boys } & \multicolumn{4}{|c|}{ Girls } & \multirow{2}{*}{\multicolumn{2}{|c|}{$\begin{array}{c}\text { Total } \\
\text { Mean }(\mathrm{n}=186)\end{array}$}} & \multirow{3}{*}{$\begin{array}{c}\mathrm{p} \text { values } \\
0.648\end{array}$} \\
\hline & \multicolumn{2}{|c|}{ Mean $(\mathrm{n}=91)$} & \multirow{2}{*}{$\begin{array}{c}\text { Minimum } \\
122.6\end{array}$} & \multirow{2}{*}{$\begin{array}{c}\text { Maximum } \\
150.5\end{array}$} & \multicolumn{2}{|c|}{ Mean $(\mathrm{n}=95)$} & \multirow{2}{*}{$\begin{array}{c}\text { Minimum } \\
120.0\end{array}$} & \multirow{2}{*}{$\begin{array}{c}\text { Maximum } \\
152.7\end{array}$} & & & \\
\hline & 134.6 & $(5.62)$ & & & 135.1 & $(6.97)$ & & & 134.8 & $(6.33)$ & \\
\hline Weight (kg) & 31.1 & $(5.33)$ & 22.6 & 48.8 & 32.3 & $(7.75)$ & 21.7 & 69.2 & 31.7 & (6.69) & 0.236 \\
\hline Body mass Index & 17.1 & $(2.15)$ & 14.1 & 24.8 & 17.6 & $(3.07)$ & 12.7 & 31.3 & 17.3 & $(2.66)$ & 0.230 \\
\hline $\begin{array}{l}\text { Total cholesterol } \\
\qquad(\mathrm{mg} / \mathrm{dL})\end{array}$ & 169.1 & $(23.68)$ & 109.0 & 247.0 & 176.4 & $(26.01)$ & 121.0 & 279.0 & 172.8 & $(25.10)$ & 0.049 \\
\hline $\begin{array}{l}\text { LDL-cholesterol } \\
\qquad(\mathrm{mg} / \mathrm{dL})\end{array}$ & 92.3 & $(22.00)$ & 46.0 & 169.0 & 98.2 & $(25.00)$ & 56.0 & 197.0 & 95.3 & $(23.72)$ & 0.090 \\
\hline $\begin{array}{l}\text { HDL-cholesterol } \\
\qquad(\mathrm{mg} / \mathrm{dL})\end{array}$ & 60.1 & $(9.11)$ & 37.0 & 88.0 & 61.4 & (12.09) & 38.0 & 93.0 & 60.7 & (10.73) & 0.403 \\
\hline $\begin{array}{l}\text { Triglyceride } \\
(\mathrm{mg} / \mathrm{dL})\end{array}$ & 81.6 & $(52.81)$ & 27.0 & 436.0 & 73.6 & $(35.17)$ & 30.0 & 246.0 & 77.5 & $(44.73)$ & 0.228 \\
\hline
\end{tabular}

Value are expressed as mean (SD).

Table 2. Serum levels $(\mathrm{mg} / \mathrm{dL})$ in children of public elementary school.

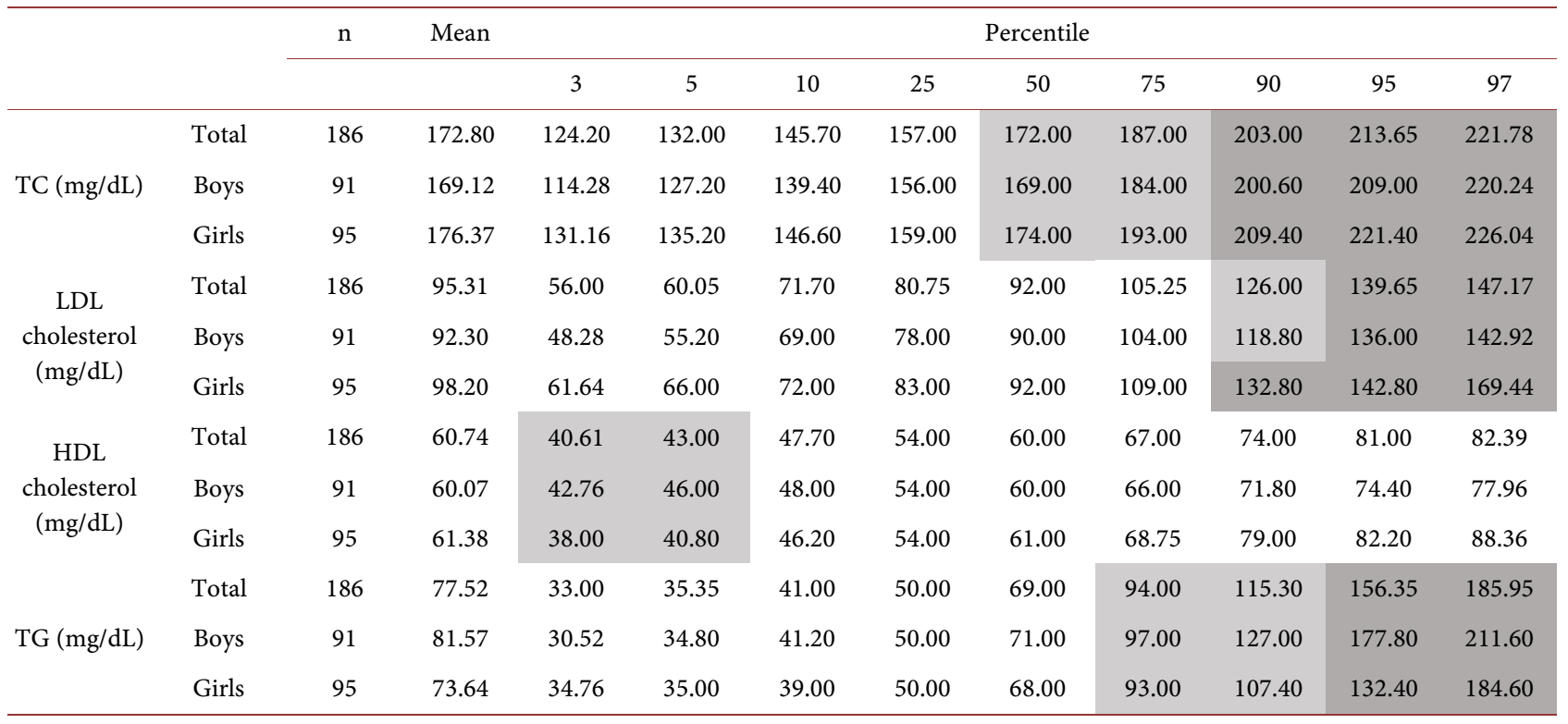

TC level was categorized as follows: acceptable < $190 \mathrm{mg} / \mathrm{dL}$; borderline $190-219 \mathrm{mg} / \mathrm{dL}$; and high $>220 \mathrm{mg} / \mathrm{dL}$. The LDL chpoesterol level was also categorized into: acceptable < $110 \mathrm{mg} / \mathrm{dL}$; borderline $110-139 \mathrm{mg} / \mathrm{dL}$; and high $>140 \mathrm{mg} / \mathrm{dL}$. The cut-off value in HDL cholesterol was $40 \mathrm{mg} / \mathrm{dL}$ and in TG was determined to be $140 \mathrm{mg} / \mathrm{dL}$ [12]. —:The border line high value which Irwin Benuck showed [27]. —:The high value which Irwin Benuck showed [27].

Table 3. Time spent by gender.

\begin{tabular}{clccccc}
\hline & \multicolumn{2}{c}{ Boys $(\mathrm{n}=91)$} & \multicolumn{2}{c}{ Girls $(\mathrm{n}=95)$} & \multicolumn{2}{c}{$\mathrm{p}$ values } \\
\hline Minutes for Sleeping (m)/day & 524.2 & $(42.29)$ & 538.2 & $(47.51)$ & 0.035 \\
Minutes for Game (m)/day & 136.7 & $(94.49)$ & 120.8 & $(106.37)$ & 0.285 \\
Minutes for Exercise (m)/day & 134.7 & $(111.95)$ & 95.0 & $(90.79)$ & 0.009 \\
\hline
\end{tabular}

Value are expressed as mean (SD).

discussing health guidance from school $(\mathrm{P}=0.0075)$, and undergoing health checkups $(\mathrm{P}<0.001)$ but not knowing one's own blood test results $(\mathrm{P}=0.0023)$. 
Table 4. Explanation of the alternatives of questionnaire.

\begin{tabular}{|c|c|}
\hline Objective variable & Alternatives \\
\hline Pupils' Sex & boy: 1 , girl: 0 \\
\hline \multicolumn{2}{|l|}{ Body Mass Index } \\
\hline \multicolumn{2}{|l|}{ Guardian } \\
\hline Sex of the guardian who answered & male: 1 , female: 0 \\
\hline $\begin{array}{l}\text { Does your fourth-grade child have any older brothers } \\
\text { and/or sisters? }\end{array}$ & no: 1 , yes: 0 \\
\hline Do you eat breakfast? & yes: 1 , no: 0 \\
\hline Do you think that children should eat a lot? & yes: 1 , no: 0 \\
\hline Who chooses your child's snacks? & child: 1 , other: 0 \\
\hline $\begin{array}{l}\text { What are you most concerned about snacks for your } \\
\text { child? }\end{array}$ & quantity: 1 , other: 0 \\
\hline $\begin{array}{l}\text { Does your child eat any snacks before dinner on } \\
\text { weekdays? }\end{array}$ & $\begin{array}{l}\text { every day: } 1 \text {, sometime: } 2 \text {, seldom: } 3 \text {, } \\
\text { no: } 4\end{array}$ \\
\hline Do you worry about your child skipping meals? & yes: 1 , a sometimes: 2 , seldom: 3 , no: 4 \\
\hline $\begin{array}{l}\text { Do you make sure that your child does not overeat } \\
\text { heavily seasoned foods? }\end{array}$ & yes: 1 , sometimes: 2 , seldom: 3 , no: 4 \\
\hline $\begin{array}{l}\text { Do you make sure that your child does not drink too } \\
\text { many juices? }\end{array}$ & yes: 1 , sometimes: 2 , seldom: 3 , no: 4 \\
\hline $\begin{array}{l}\text { Do you make sure that your child does not overeat } \\
\text { snacks? }\end{array}$ & yes: 1 , sometimes: 2 , seldom: 3 , no: 4 \\
\hline $\begin{array}{l}\text { Do you make sure that your child eats plenty of } \\
\text { vegetables? }\end{array}$ & no: 1 , seldom: 2 , sometimes: 3 , yes: 4 \\
\hline $\begin{array}{l}\text { Do you make sure that your child does not have any } \\
\text { likes and dislikes? }\end{array}$ & no: 1 , seldom: 2 , sometimes: 3 , yes: 4 \\
\hline Do you make sure that your child enjoys mealtimes? & no: 1 , seldom: 2 , sometimes: 3 , yes: 4 \\
\hline $\begin{array}{l}\text { Do you make sure that your child eats rice and } \\
\text { accompanying dishes alternatively? }\end{array}$ & no: 1 , seldom: 2 , sometimes: 3 , yes: 4 \\
\hline $\begin{array}{l}\text { Do you read all the school lunch program notices } \\
\text { handed out from school? }\end{array}$ & no: 1 , seldom: 2 , sometimes: 3 , yes: 4 \\
\hline $\begin{array}{l}\text { Do you think that schools should give guidance to } \\
\text { children to exercise? }\end{array}$ & no: 1 , seldom: 2 , sometimes: 3 , yes: 4 \\
\hline $\begin{array}{l}\text { Do you think that children should be provided with an } \\
\text { exercise-friendly environment? }\end{array}$ & yes: 1 , sometimes: 2 , seldom: 3 , no: 4 \\
\hline $\begin{array}{l}\text { Do you think that your child's body weight matches } \\
\text { his/her height? }\end{array}$ & yes: 1 , sometimes: 2 , seldom: 3 , no: 4 \\
\hline $\begin{array}{l}\text { Do you think that children should learn about lifestyle } \\
\text { diseases in school? }\end{array}$ & no: 1 , yes: 0 \\
\hline $\begin{array}{l}\text { Do you discuss with your children health guidance } \\
\text { issues learned in school? }\end{array}$ & no: 1 , yes: 0 \\
\hline Have you had a health checkup in the last year? & no: 1 , yes: 0 \\
\hline Do you know the results of your own blood tests? & no: 1 , yes: 0 \\
\hline Child & \\
\hline How many hours do you sleep on school nights? & minutes \\
\hline
\end{tabular}




\section{Continued}

Do you ever wake up in the morning feeling still sleepy and not refreshed?

Do you have a bowel movement every day?

Do you know your own body weight?

Please share with us what you think of your body shape.

Have you ever tried to reduce your body weight to become slimmer?

Are you careful not to be too skinny or too overweight?

How many hours in a day do you play games or are you on your phone after coming home from school?

Do you ever feel sluggish or become tired easily?

Do you ever feel irritated?

Do you think that it is good to eat lots of French fries because they are made of vegetables?

Do you think that the dietary composition of meals and exercise have no effect on the results of your blood tests?

Other than PE at school, how long do you exercise or play outdoors in a day?

Do you think that regular exercise leads to preventing illnesses?

On sunny days, do you engage in any physical play activities during break time?

Can you make time to exercise or do sports?

Do you eat breakfast?

Do you ever have second helpings during school lunch?

Do you ever eat snacks after dinner?

Do you ever eat snacks continuously while watching TV?

Do you think that your current dietary intake is good for your body?

Which do you prefer, bland tasting or heavily seasoned food?

Do you frequently eat deep fried food?

Are you careful to eat slowly and chew your food well during meals?

Do you try to always eat breakfast, lunch, and dinner?

Are you careful not to eat too many heavily seasoned foods?

Do you try to eat a variety of different kinds of food?

Are you careful not to eat too many salty foods?

Do you try to eat dairy products?

Do you try not to have likes and dislikes? yes: 1 , sometimes: 2 , seldom: 3 , no: 4 no: 1 , seldom: 2 , sometimes: 3 , yes: 4 no: 1 , seldom: 2 , sometimes: 3 , yes: 4 very fat: 1 , fat: 2 , thin: 3 , very thin: 4 yes: 1 , sometimes: 2 , seldom: 3 , no: 4 no: 1 , seldom: 2 , sometimes: 3 , yes: 4 minutes

yes: 1 , sometimes: 2 , seldom: 3 , no: 4 yes: 1 , sometimes: 2 , seldom: 3 , no: 4 yes: 1 , sometimes: 2 , seldom: 3 , no: 4 yes: 1 , sometimes: 2 , seldom: 3 , no: 4 minutes

yes: 1 , sometimes: 2 , seldom: 3 , no: 4 no: 1 , yes: 2

no: 1 , seldom: 2 , sometimes: 3 , yes: 4 no: 1 , seldom: 2 , sometimes: 3 , yes: 4 yes: 1 , sometimes: 2 , seldom: 3 , no: 4 every day: 1 , sometimes: 2 , rarely: 3 , no: 4

every day: 1 , sometime: 2 , rarely: 3 , no: 4

no: 1 , seldom: 2 , sometimes: 3 , yes: 4 yes: 1 , no: 2

yes: 1 , sometimes: 2 , seldom: 3 ,no: 4 no: 1 , seldom: 2 , sometimes: 3 , yes: 4 no: 1 , seldom: 2 , sometimes: 3 , yes: 4 yes: 1 , sometimes: 2 , seldom: 3 , no: 4 no: 1 , seldom: 2 , sometimes: 3 , yes: 4 yes: 1 , sometimes: 2 , seldom: 3 , no: 4 no: 1 , seldom: 2 , sometimes: 3 , yes: 4 no: 1 , seldom: 2 , sometimes: 3 , yes: 4 
Table 5. Customs related to children's cholesterol measurement.

\begin{tabular}{|c|c|c|c|c|c|c|c|c|}
\hline \multirow{2}{*}{ Objective variable } & TC & is high & LDL & is high & HDL & is low & TG & is high \\
\hline & Estimate & $\mathrm{p}$ values & Estimate & $p$ values & Estimate & $\mathrm{p}$ values & Estimate & $p$ values \\
\hline intercept & 5.0283 & $<0.001^{* * *}$ & 4.5747 & $<0.0001^{* * *}$ & 4.451444 & $<0.0001^{* * *}$ & 4.13394 & $<0.0001^{\star * *}$ \\
\hline pupils' Sex & -0.0379 & 0.1148 & 0.0064 & 0.8519 & 0.10372 & $0.0002^{* * *}$ & 0.1208 & 0.0656 \\
\hline Body Mass Index & 0.0043 & 0.3495 & 0.0083 & 0.1947 & 0.01367 & $0.0135^{\star}$ & 0.0190 & 0.2004 \\
\hline \multicolumn{9}{|l|}{ Guardian } \\
\hline Sex of the parent & & & & & -0.1074 & $0.0390^{*}$ & & \\
\hline $\begin{array}{l}\text { Does your fourth-grade child have } \\
\text { any older brothers and/or sisters? }\end{array}$ & & & & & -0.0534 & $0.0289^{*}$ & & \\
\hline
\end{tabular}

Do you eat breakfast?

Do you think that children should eat a lot?

Who chooses your child's snacks?

What are you most concerned about regarding snacks for your child?

Does your child eat any snacks before dinner on weekdays?

Do you worry about your child skipping meals?

Do you make sure that your child does not overeat heavily seasoned foods?

Do you make sure that your child does not drink too many juices?

Do you make sure that your child does not overeat snacks?

Do you make sure that your child eats plenty of vegetables?

Do you make sure that your child does not have any likes and dislikes?

Do you make sure that your child enjoys mealtimes?

Do you make sure that your child eats rice and accompanying dishes alternatively?

Do you read all the school lunch program notices handed out from school?

Do you think that schools should give guidance to children to exercise?

Do you think that children should be provided with an exercise-friendly environment?

Do you think that your child's body weight matches his/her height?
$-0.2083 \quad 0.0390^{*}$

$-0.1160 \quad 0.0099^{* *}$

$0.0574 \quad 0.0433^{*}$

$-0.2825 \quad 0.0006^{* * *}$

$-0.0729 \quad 0.0455^{\star}$

$\begin{array}{ll}0.0675 & 0.0009^{* * *} \\ 0.0510 & 0.0077^{* *}\end{array}$

$0.0429 \quad 0.0206^{*}$

$0.0224 \quad 0.0845$

$-0.0496 \quad 0.0075^{* *}$

$-0.0466 \quad 0.0058^{* *}$

$-0.0518 \quad 0.0059^{* *}$

$0.04920 .0019^{* *}$
$0.0578-0.0041^{* *}$

$-0.0586 \quad 0.0039^{* *}$
$-0.0760 \quad 0.0438^{\star}$

0.0529 


\section{Continued}

Do you think that children should learn about lifestyle diseases in school?

Do you discuss with your children health guidance issues learned in school?

Have you had a health checkup in the last year?

Do you know the results of your own blood tests?

Child

How many hours do you sleep on school nights?

Do you ever wake up in the morning feeling still sleepy and not refreshed?

Do you have a bowel movement every day?

Do you know your own body weight?

Please share with us what you think of your body shape.

Have you ever tried to reduce your body weight to become slimmer?

Are you careful not to be too skinny or too overweight?

How many hours in a day do you play games or are you on your phone after coming home from school?

Do you ever feel sluggish or become tired easily?

Do you ever feel irritated?

Do you think that it is good to eat lots of French fries because they are made of vegetables?

$-0.0403$

0.1179

0.0302

0.1435

$-0.0691$ $0.0068^{* *}$

Do you think that the dietary composition of meals and exercise have no effect on the results of your $0.0476 \quad 0.0427^{*}$ blood tests?

Other than PE at school, how long

do you exercise or play outdoors in a
day?

$-0.0507$

Do you think that regular exercise leads to preventing illnesses?

$-0.0281$

0.1314

$-0.0684$

On sunny days, do you engage in any physical play activities during break time?

$0.0765 \quad 0.0584$

$-0.1361 \quad 0.0016^{* *}$

$$
-0.0356 \quad 0.1081
$$

Can you make time to exercise or do sports?

$\begin{array}{llll}0.0444 & 0.0314^{*} & 0.0689 & 0.0211^{*}\end{array}$

Do you eat breakfast?

$-0.0523$

$-0.1559$

$<0.0001^{\star * *}$ 


\section{Continued}

Do you ever have second helpings

during school lunch?

Do you ever eat snacks after dinner?

Do you ever eat snacks continuously while watching TV?

Do you think that your current dietary intake is good for your body?

Which do you prefer, bland tasting or heavily seasoned food?

Do you frequently eat deep fried food?

Are you careful to eat slowly and chew your food well during meals?

Do you try to always eat breakfast, lunch, and dinner?

Are you careful not to eat too many heavily seasoned foods?

Do you try to eat a variety of different kinds of food?

Are you careful not to eat too many salty foods?

Do you try to eat dairy products?

Do you try not to have likes and dislikes?

Adjusted R-squared

${ }^{* * *}: \mathrm{P}<0.001 .{ }^{* *}: \mathrm{P}<0.01 .{ }^{*}: \mathrm{P}<0.05$
0.0237

0.1217

0.0480

$0.0372^{*}$

$0.0457 \quad 0.0938$

0.0335

0.1027

$0.0330 \quad 0.0768$

$\begin{array}{cc}-0.0943 & 0.0152^{*} \\ 0.0644 & 0.0059^{* *}\end{array}$

$0.0461 \quad 0.0379^{*}$

$0.0860 \quad 0.0327^{*}$

$\begin{array}{llllll}0.0691 & 0.0032^{* *} & 0.1685 & <0.0001^{* * *} & 0.1200 & 0.0202^{*}\end{array}$

$\begin{array}{llll}-0.0344 & 0.1240 & -0.1057 & 0.0007^{* * *}\end{array}$

$-0.0416 \quad 0.0839$

0.0343

0.0609

$-0.06350 .0024^{* *}$

$\begin{array}{llll}-0.0429 & 0.0095^{* *} & -0.0887 & 0.0003^{* * *}\end{array}$

0.22

0.44

0.28

0.14

Variables of children associated with higher LDL cholesterol levels were as follows: feeling irritated $(\mathrm{P}=0.0009)$, shorter exercise time $(\mathrm{P}=0.0080)$, skipping breakfast $(\mathrm{P}<0.0001)$, not eating a wide variety of foods $(\mathrm{P}=0.0007)$, having likes and dislikes $(\mathrm{P}=0.0003)$, not eating deep fried foods $(\mathrm{P}=0.0059)$, and not eating heavily seasoned foods $(\mathrm{P}<0.0001)$. Some of these reflect the possession of health-promoting knowledge, but there are examples of misunderstandings such as a positive view towards eating a large amount of French fries because they are vegetables $(P=0.0059)$ and a belief that exercise does not help to prevent diseases $(\mathrm{P}=0.0097)$.

Variables of parents associated with lower HLD cholesterol levels of children were as follows: not checking overeating of snacks $(\mathrm{P}=0.0075)$, not ensuring sufficient vegetable consumption ( $\mathrm{P}=0.0058)$, and enjoying eating $(\mathrm{P}=0.0019)$. The corresponding variables for children were as follows: desire to lose weight $(\mathrm{P}=0.0082)$, being inactive during break time $(\mathrm{P}=0.0016)$, and not eating dairy products $(P=0.0024)$. Lifestyle variables of children associated with higher TG levels were as follows: eating snacks before dinner $(P=0.0455)$, not eating rice and accompanying dishes alternatively $(\mathrm{P}=0.0438)$, not easily fatigued $(\mathrm{P}=$ $0.0122)$, and not caring about eating heavily seasoned foods $(P=0.0202)$. 
Variables of parents associated with higher TG levels of children were as follows: eating snacks before dinner $(\mathrm{P}=0.0455)$ and not caring about the way to eat meals $(P=0.0438)$. The corresponding variables for children were as follows: not easily fatigued $(P=0.0122)$ and caring about not eating heavily seasoned foods $(\mathrm{P}=0.0202)$.

\section{Discussion}

\subsection{The Need for School-Based Cholesterol Screenings}

The NHLBI has established two goals for the prevention of CVD [20]: 1) prevent the increase of CVD risk; and 2) prevent the development of future CVD through risk factor management. Identifying dyslipidemia in children through screening leads to preventing the increase of CVD risk. Screening is highly significant, especially for identifying familial dyslipidemia, which is known to affect one in five hundred people [19] [21] [22] [23]. Therefore, an increase in the screening rate would greatly contribute to prevention efforts [23]. A study based on the NHLBI guidelines was conducted at pediatric clinics in five different towns, and found that the screening rates before and after implementing the NHLBI guidelines were $17.1 \%$ and $20.1 \%$, respectively [24]. However, the screening rate of fourth-grade students in our study conducted at a public elementary school was $83.6 \%$. Considering the significance of screening tests, it is very important to conduct screenings at public elementary schools.

The other goal is risk factor management. As recommended by the NHLBI [20], risk management for children is essential, and guidance must be provided to deter future risks in children. School-based health guidance has been implemented in the past to address the prevention of lifestyle diseases [25] [26]. However, the children are not given an opportunity to know their own cholesterol levels, as cholesterol testing is not a part of the school-based health checkups. According to different cut-off reference values from several studies [12] [13] [14] [15], our study results show that there are students with high cholesterol levels, as shown in Table 2. When the reference values established by the local government were used, there were no children that required medical assistance and $3.5 \%$ were flagged as requiring guidance. According to the values proposed by Benuck [27], children around the 50th to 70th percentile had borderline cholesterol levels. This is undoubtedly not a good situation. In the present school system, these children have no way of knowing their cholesterol test results, since, as stated above, cholesterol testing is not routinely performed during school-based health checkups. Knowing one's own cholesterol level is the first step in increasing interest in cholesterol. This knowledge has the potential to be used as teaching material in health promotion education for raising self-awareness of lifestyle diseases.

\subsection{Lifestyle Issues that Require Group Guidance from Schools}

Family life and values are extremely important for elementary school-aged children in reducing their future CVD risk. By investigating not only the students' but 
also the parents' situation, we identified lifestyle issues that could be improved by informing parents of their children's cholesterol test results. Lifestyle issues of children that emerged through the school-based cholesterol testing were examined individually based on the different cholesterol types.

\subsubsection{Total Cholesterol}

Parents' situations that had an association with high TC levels were examined. Skipping breakfast was associated with high TC levels. In the case of the children, skipping breakfast, having likes and dislikes, past dieting experience, shorter exercise time, and understanding that diet and exercise have no effect on blood test results were associated with high TC levels. These variables coincided with a situation that leads to high cholesterol levels. In addition, not feeling sluggish in the morning, having time to exercise, and being careful not to eat heavily seasoned foods were associated with high TC levels. These were variables that demonstrated the children are healthy and have no physical symptoms. Both parents and children seemed to be concerned about obesity. The short exercise time despite having time to exercise is due to their misunderstanding that diet and exercise have no effect on blood test results. Therefore, children's exercise time may be increased by informing the parents of their children's TC levels and correcting the parents' misunderstanding.

\subsubsection{Low-Density Lipoprotein (LDL) Cholesterol}

Parents' situations that were associated with high LDL cholesterol levels in their children were examined and found to be as follows: not supervising the amount of snacks, not addressing likes and dislikes, not worried about skipping meals, and not discussing health guidance from school. This illustrates that parents are not paying attention to their children's lifestyle. In addition, children's high LDL cholesterol levels were related to parents' general knowledge of diet and exercise, as well as their understanding of their children's body shape. In fact, the children's high LDL cholesterol levels were due to the lack of concern for the children. Regarding the children's perspective on lifestyles and values based on their responses, high LDL cholesterol levels were associated with the following: viewing French fries as being vegetables, not believing that exercise can prevent illnesses, shorter exercise time despite having time to exercise, skipping breakfast, preference for heavily seasoned foods, not eating a wide variety of foods, and having likes and dislikes. These variables coincide with factors that elevate LDL levels. These issues have emerged despite the fact that the relationship of diet and exercise with lifestyle diseases is being taught as part of "shokuiku", the food and nutrition education program in Japan [28]. The need to disseminate accurate information was emphasized. Variables associated with high LDL cholesterol levels illustrated that reasons children being healthy were as follows: not feeling irritated, having good bowel of movements, and not having second helpings for lunch. It is difficult for children to be interested in their LDL cholesterol levels without knowing their own test results, as well as not having any noticeable symptoms. Knowing their own LDL cholesterol levels from the results of the 
school-based health checkups would serve as a good opportunity to acquire accurate information.

\subsubsection{High-Density Lipoprotein (HDL) Cholesterol}

Parents' situations that were associated with low HDL cholesterol levels in children were examined. The most notable factor was who chooses a child's snack. A low HDL cholesterol level was associated with a child choosing his or her own snack. Not paying attention to overeating of snacks was also related to low HDL cholesterol levels. These findings point to the fact that cholesterol levels are affected by whether parents are paying attention to their children. Cholesterol testing would direct the attention of parents to their children's cholesterol levels. However, guidance is still needed so that 10 -year-old children can exercise selfcontrol in their day-to-day lives without having to be cautioned by parents. The frequency of snacking and eating snacks on one's own increases in early adolescence. From a nutritional perspective, a 10-year-old child does not need snacks. However, snacks not only have nutritional value but also have a refreshing effect on the child. The daily recommended caloric intake from snacks should be about $10 \%$. In other words, children need to learn to choose snacks that are approximately $200 \mathrm{kcal}[28]$ per day.

\subsubsection{Triglycerides (TG)}

According to the parents' responses, a lifestyle situation that had an association with high TG levels was eating snacks before dinner. There were no children's responses related with high TG.

\subsubsection{High-Priority Lifestyle Habits That Require Guidance}

The following variables were associated with more than 2 types of cholesterol levels: parents warning children to avoid overeating snacks, increasing exercise time, eating breakfast, avoiding heavily seasoned foods, eliminating likes and dislikes to eat a wide variety of foods, and eating dairy products. These require specific, focused guidance. Addressing lifestyle issues in the family while discussing a child's cholesterol levels is a CVD risk management opportunity for the family and the community. Investigating the risk of diseases related to CVD among all school children is a prevention activity that uses the population approach. All respective local governments are expected to address ways for encouraging a lifestyle that decreases risks [26]. One specific strategy is childhood cholesterol testing. It must be targeted to all the children in the area as part of health promotion education. The children's cholesterol test results should be used by the entire family as educational material to acquire healthy lifestyle habits [24] to reduce the future risk of non-obese [29] individuals being at high risk for heart disease.

\section{Study Limitations}

The relationships among carotid artery intima-media thickness (IMT), arteriosclerosis, and cholesterol levels of the 10-year-old children who showed border- 
line cholesterol levels should be investigated. A cohort study should then be conducted to investigate changes in cholesterol levels and to determine the future incidence of CVD. If cholesterol screening is used as educational material, the effects on children and parents need to be verified.

\section{Conclusion}

In order to verify the role and necessity in CVD prevention for the child's cholesterol test in a public school, the distribution of the child's cholesterol and the relevance to the cholesterol value, a child, and the guardian's life were considered. Eighty-three percent (189/226) of the eligible school children in the city participated in the cholesterol testing. Children's cholesterol levels were poor. The cholesterol test in the public school can raise an enforcement rate easily. Though in the present school system, these children have no way of knowing their cholesterol test results, knowing one's own cholesterol level is the first step in increasing interest in cholesterol. Cholesterol levels were associated to the situation with the children and their guardians. The children had the correct knowledge about their food habits. However, their parents consider the different food choice about their children. The children's cholesterol test results should be used by the entire family as educational material to acquire healthy lifestyle habits to reduce the future risk of non-obese individuals being at high risk for heart disease. From childhood, along with the parents, there is a need to learn about cholesterol for CVD prevention.

\section{Conflict of Interest}

The authors declare that they have no conflicts of interest.

\section{References}

[1] World Health Organization (2016) Cardiovascular Diseases (CVDs): Fact Sheet. http://www.who.int/mediacentre/factsheets/fs317/en/

[2] The Ministry of Health, Labour and Welfare, Japan (2015) Summary Report of Vital Statistics of Japan (Final Data) Cause-of-Death Classification. (In Japanese) http://www.mhlw.go.jp/toukei/saikin/hw/jinkou/kakutei15/dl/11_h7.pdf

[3] Berenson, G.S., Srinivasan, S.R., Bao, W., Newman, W.P., Tracy, R.E. and Wattigney, W.A. (1998) Association between Multiple Cardiovascular Risk Factors and Atherosclerosis in Children and Young Adults. The Bogalusa Heart Study. The New England Journal of Medicine, 338, 1650-1656. https://doi.org/10.1056/NEJM199806043382302

[4] Cleeman, J.I. and Lenfant, C. (1998) The National Cholesterol Education Program: Progress and Prospects. Journal of the American Medical Association, 280, 2099 2104. https://doi.org/10.1001/jama.280.24.2099

[5] Jousilahti, P., Vartiainen, E., Tuomilehto, J. and Puska, P. (1999) Sex, Age, Cardiovascular Risk Factors, and Coronary Heart Disease: A Prospective Follow-Up Study of 14786 Middle-Aged Men and Women in Finland. Circulation Journal, 99, 1165-1172. https://doi.org/10.1161/01.CIR.99.9.1165

[6] Lakatta, E.G. (2002) Age-Associated Cardiovascular Changes in Health: Impact on Cardiovascular Disease in Older Persons. Failure Heart Reviews, 7, 29-49. 
https://doi.org/10.1023/A:1013797722156

[7] Nguyen, D., Kit, B. and Carroll, M. (2015) Abnormal Cholesterol among Children and Adolescents in the United States, 2011-2014. NCHS Data Brief, 228, 1-8.

https://www.cdc.gov/nchs/data/databriefs/db228.pdf

[8] Raitakari, O.T., Juonala, M., Kähönen, M., Taittonen, L., Laitinen, T. and MäkiTorkko, N., et al. (2003) Cardiovascular Risk Factors in Childhood and Carotid Artery Intima-Media Thickness in Adulthood: The Cardiovascular Risk in Young Finns Study. Journal of the American Medical Association, 290, 2277-2283. https://doi.org/10.1001/jama.290.17.2277

[9] Tan, F., Okamoto, M., Suyama, A. and Miyamoto, T. (2000) Tracking of Cardiovascular Risk Factors and a Cohort Study on Hyperlipidemia in Rural Schoolchildren in Japan. Journal of Epidemiology, 10, 255-261.

https://doi.org/10.2188/jea.10.255

[10] Yamazaki, Y. (2008) Relation of Adiposity Rebound Age to Serum Small Dense Low-Density Lipoprotein in Young Childhood. Dokkyo Journal of Medical Sciences, 35, 7-12.

http://ci.nii.ac.jp/els/110006966534.pdf?id=ART0008875110\&type=pdf\&lang=jp\&h ost=cinii\&order_no $=\& p p v \_t y p e=0 \& l a n g \_s w=\& n o=1481690250 \& c p=$

[11] Kouda, K., Nakamura, H., Tokunaga, R. and Takeuchi, H. (2004) Trends in Levels of Cholesterol in Japanese Children from 1993 through 2001. Journal of Epidemiology, 14, 78-82. https://doi.org/10.2188/jea.14.78

[12] Okada, T., Murata, M., Yamauchi, K. and Harada, K. (2002) New Criteria of Normal Serum Lipid Levels in Japanese Children: The Nationwide Study. Pediatric International, 44, 596-601. https://doi.org/10.1046/j.1442-200x.2002.01634.x

[13] Kit, B.K., Carroll, M.D., Lacher, D.A., Sorlie, P.D., De Jesus, J.M. and Ogden, C. (2012) Trends in Serum Lipids among US Youths Aged 6 to 19 Years, 1988-2010. Journal of the American Medical Association, 308, 591-600. https://doi.org/10.1001/jama.2012.9136

[14] Margolis, K.L., Greenspan, L.C., Trower, N.K., Daley, M.F., Daniels, S.R., Lo, J.C., et al. (2014) Lipid Screening in Children and Adolescents in Community Practice: 2007 to 2010. Circulation: Cardiovascular Quality and Outcomes, 7, 718-726. https://doi.org/10.1161/circoutcomes.114.000842

[15] Kwiterovich, P.O. and Gidding, S.S. (2012) Universal Screening of Cholesterol in Children. Clinical Cardiology, 35, 662-664. https://doi.org/10.1002/clc.22050

[16] Tokgözoglu, L., Ros, E., Kastelein, J.P., Blom, D. and Deanfield, K. (2014) Premature Heart Attacks: Bad Lifestyle, Bad Luck, or Bad Genes? Summary of Presentations from the Aegerion Pharmaceuticals-Supported Symposium. European Medical Journal Cardiology, 2, 46-53.

[17] McCrindle, B.W., Kwiterovich, P.O., McBride, P.E., Daniels, S.R. and Kavey, R.E. (2012) Guidelines for Lipid Screening in Children and Adolescents: Bringing Evidence to the Debate. Pediatrics, 130, 353-356. https://doi.org/10.1542/peds.2012-1137

[18] Vinci, S.R., Rifas-Shiman, S.L., Cheng, J.K., Mannix, R.C., Gillman, M.W. and de Ferranti, S.D. (2014) Cholesterol Testing among Children and Adolescents during Health Visits. Journal of the American Medical Association, 311, 1804-1807. https://doi.org/10.1001/jama.2014.2410

[19] Schroeder, A.R. and Redberg, R.F. (2012) Cholesterol Screening and Management in Children and Young Adults Should Start Early-NO! Clinical Cardiology, 35, 665-668. https://doi.org/10.1002/clc.22075

[20] National Heart, Lung, and Blood Institute (2012) Expert Panel on Integrated Guide- 
lines for Cardiovascular Health and Risk Reduction in Children and Adolescents: Summary Report. https://www.nhlbi.nih.gov/files/docs/peds_guidelines_sum.pdf

[21] Marks, D., Thorogood, M., Neil, H.A., Wonderling, D. and Humphries, S.E. (2003) Comparing Costs and Benefits over a 10 Year Period of Strategies for Familial Hypercholesterolaemia Screening. Journal of Public Health Medicine, 25, 47-52. https://doi.org/10.1093/pubmed/fdg010

[22] Haney, E.M., Huffman, L.H., Bougatsos, C., Freeman, M., Steiner, R.D. and Nelson, H.D. (2007) Screening and Treatment for Lipid Disorders in Children and Adolescents: Systematic Evidence Review for the US Preventive Services Task Force. Pediatrics, 120, e189-e214. https://doi.org/10.1542/peds.2006-1801

[23] Pang, J., Martin, A.C., Mori, T.A., Beilin, L.J. and Watts, G.F. (2016) Prevalence of Familial Hypercholesterolemia in Adolescents: Potential Value of Universal Screening? The Journal of Pediatrics, 170, 315-316.

https://doi.org/10.1016/j.jpeds.2015.11.019

[24] Wilson, D.P., Davis, S., Matches, S., Shah, D., Leung-Pineda, V., Mou, M., et al. (2015) Universal Cholesterol Screening of Children in Community-Based Ambulatory Pediatric Clinics. Journal of Clinical Lipidology, 9, S88-S92. https://doi.org/10.1016/j.jacl.2015.05.006

[25] Ministry of Education, Culture, Sports, Science and Technology-Japan (2016) The Detailed Contents of The Purpose of Health. (In Japanese) http://www.mext.go.jp/b_menu/shingi/chukyo/chukyo3/022/siryo/06082912/002/00 3.htm

[26] De Ferranti, S.D. (2012) Declining Cholesterol Levels in US Youths: A Reason for Optimism. Journal of the American Medical Association, 308, 621-622. https://doi.org/10.1001/jama.2012.9621

[27] Benuck, I. (2015) Point: The Rationale for Universal Lipid Screening and Treatment in Children. Journal of Clinical Lipidology, 9, S93-S100. https://doi.org/10.1016/j.jacl.2015.03.104

[28] Ministry of Agriculture, Forestry and Fisheries (2015) Be Careful of Overeating of Confectionery. (In Japanese) http://www.maff.go.jp/j/balance_guide/b_sizai/pdf/oyako_2.pdf

[29] Kadota, A., Hozawa, A., Okamura, T., Kadowak, T., Nakmaura, K., Murakami, Y., et al. (2007) Relationship between Metabolic Risk Factor Clustering and Cardiovascular Mortality Stratified by High Blood Glucose and Obesity. Diabetes Care, 30, 1533-1538. https://doi.org/10.2337/dc06-2074 
Submit or recommend next manuscript to SCIRP and we will provide best service for you:

Accepting pre-submission inquiries through Email, Facebook, LinkedIn, Twitter, etc. A wide selection of journals (inclusive of 9 subjects, more than 200 journals)

Providing 24-hour high-quality service

User-friendly online submission system

Fair and swift peer-review system

Efficient typesetting and proofreading procedure

Display of the result of downloads and visits, as well as the number of cited articles Maximum dissemination of your research work

Submit your manuscript at: http://papersubmission.scirp.org/

Or contact health@scirp.org 